\title{
Experimental and theoretic investigations of thermal behavior of a seasonal water pit heat storage
}

Fan, Jianhua; Huang, Junpeng; Chatzidiakos, Angelos ; Furbo, Simon

Publication date:

2017

Document Version

Peer reviewed version

Link back to DTU Orbit

Citation (APA):

Fan, J., Huang, J., Chatzidiakos, A., \& Furbo, S. (2017). Experimental and theoretic investigations of thermal behavior of a seasonal water pit heat storage. Paper presented at Solar World Congress 2017, Abu Dhabi, United Arab Emirates.

\section{General rights}

Copyright and moral rights for the publications made accessible in the public portal are retained by the authors and/or other copyright owners and it is a condition of accessing publications that users recognise and abide by the legal requirements associated with these rights.

- Users may download and print one copy of any publication from the public portal for the purpose of private study or research.

- You may not further distribute the material or use it for any profit-making activity or commercial gain

- You may freely distribute the URL identifying the publication in the public portal

If you believe that this document breaches copyright please contact us providing details, and we will remove access to the work immediately and investigate your claim. 


\title{
EXPERIMENTAL AND THEORETIC INVESTIGATIONS OF THERMAL BEHAVIOR OF A SEASONAL WATER PIT HEAT STORAGE
}

\author{
Jianhua Fan ${ }^{1}$, Junpeng Huang ${ }^{1}$, Angelos Chatzidiakos ${ }^{1}$, Simon Furbo ${ }^{1}$ \\ ${ }^{1}$ Department of Civil Engineering, Technical University of Denmark, Kgs. Lyngby, Denmark
}

\begin{abstract}
Seasonal heat storages are considered essential for district heating systems because they offer flexibility for the system to integrate different fluctuating renewable energy sources. Water pit thermal storages (PTES) have been successfully implemented in solar district heating plants in Denmark. Thermal behavior of a 75,000 $\mathrm{m}^{3}$ water pit heat storage in Marstal solar heating plant was investigated experimentally and numerically. Temperatures at different levels of the water pit storage and temperatures at different depths of the ground around the storage were monitored and analyzed. A simulation model of the water pit storage is built to investigate development of temperatures in and around the storage. The calculated temperatures are compared to the monitored temperatures with an aim to validate the simulation model. Thermal stratification in the water pit heat storage and its interaction with the ground are elucidated by calculations using the validated CFD model.
\end{abstract}

Keywords: Solar heating plants, Seasonal water pit thermal storages (PTES), Experimental investigations, Computational fluid dynamics (CFD), Thermal stratification

\section{Introduction}

Heat storages are considered essential for a district heating system with a large share of renewable energies due to the flexibility they offer to accommodate the fluctuating nature of the renewable energy sources such as wind and solar energy. The most promising heat storage solutions are tank storage systems, water pit thermal storage (PTES), aquifer thermal energy storage (ATES), borehole storage (BTES) and water-gravel pit storage (Pavlov and Olesen 2012, Heller 2000). Moreover, cases of latent heat storage using phase change materials are also investigated but there are still some barriers to overcome before applying them to large scale (Sharma etc 2009). Large scale water pit thermal energy storages are viable solutions both economically and environmentally since these stores are simple in construction and relatively cheap. Larger storage volumes lead to increased efficiency in practice, since the heat losses do not increase with the volume proportionally. With a large water pit heat storage, solar fraction of a district heating system could be significantly increased to for example $50 \%$ of the heat demand of the district heating network. PTES have been successfully used in district heating plants in Denmark, for example, in Marstal $(75,000$ $\left.\mathrm{m}^{3}\right)$, Dronningland $\left(60,000 \mathrm{~m}^{3}\right)$, Vojens $\left(200,000 \mathrm{~m}^{3}\right)$ and $\operatorname{Gram}\left(120,000 \mathrm{~m}^{3}\right)$.

Thermal behaviors of water pits as seasonal heat storages have been investigated both experimentally and theoretically. Kielsgaard Hansen et al. (1983) investigated first a small $500 \mathrm{~m}^{3}$ pilot water pit heat storage at the campus of the Technical University of Denmark. Later, Kübler et al. (1997) presented investigations on a pilot heat storage with about $600 \mathrm{~m}^{3}$ volume built in Rottweil. The pilot heat storage was applied as short term storage in connection with a combined heat and power (CHP) plant. The storage container was made of concrete with a stainless steel liner and mineral wool as insulation. The aim of the paper was to demonstrate the feasibility of the technology and to gain practical experience for the construction of larger stores. A gravel /water storage pit was built in Steinfurt, Germany (Pfeil M. 2000). The ecological compatibility of the used materials in the storage was proved. Another focus of the paper was analysis of the cost-reduction potential of the PTES (Pfeil M. 2000). Thermal behavior of a model PTES was experimentally investigated in a test rig and numerically investigated by means of CFD simulations (Change and $\mathrm{Wu}, 2017$ ). The investigated PTES was a scaled down model that facilitates measurements in a test rig. Thermal behaviors of PTES in real operation with a volume as large as $70,000 \mathrm{~m}^{3}$ was not found.

Marstal's PTES was developed, based on the experience from the small demonstration water pits, and funded under the SUNSTORE 4 project, as part of the "EU flag projects" (Kate 2013). Its aim is to increase the solar fraction of the plant up to $55 \%$ of the thermal energy production, focusing on sustainability, increased efficiency and low costs. 
Marstal's 75,000 $\mathrm{m}^{3}$ PTES was commissioned in 2012 and it has a capacity of $6.96 \mathrm{GWh}$ according to PlanEnrgi (Jensen 2014). The operating temperatures vary depending on the season and the depth of the water layer, however the pond is designed to operate in a range of $10-90{ }^{\circ} \mathrm{C}$.

The aim of the paper is to investigate thermal behavior of the large water pit heat storage in Marstal solar heating plant. Temperatures at different levels of the water pit storage and temperatures at different depths of the ground around of the storage were monitored and analyzed. A simulation model of the water pit storage is built to investigate development of temperatures in and around the storage. The calculated temperatures are compared to the monitored temperatures with an aim to validate the simulation model. Thermal behavior of the water pit heat storage and its interaction with the ground are elucidated.

\section{Measurements of the PTES in Marstal}

Located in a small island Ærø in the southern part of Denmark, the $75,000 \mathrm{~m}^{3}$ water pit heat storage has an outer dimension of $98 \mathrm{~m} \times 98 \mathrm{~m}$ excluding the dam around the storage, see Fig. 1 . The depth of water in the storage is 16 $\mathrm{m}$. An illustration of the design of the water pit thermal energy storage is given in Fig. 2. After commissioning of the PTES in 2012, detailed measurement have been carried out in in the period 2014-2016 to evaluate thermal performances of the storage. The following monitoring equipment is installed on the water pit heat storage:

< Temperature and volume flow sensors in inlet/outlet pipes

$<$ Temperature sensors inside the water storage at different levels

< Temperature sensors in the ground at different depths

\& A heat flux sensor in the floating top cover

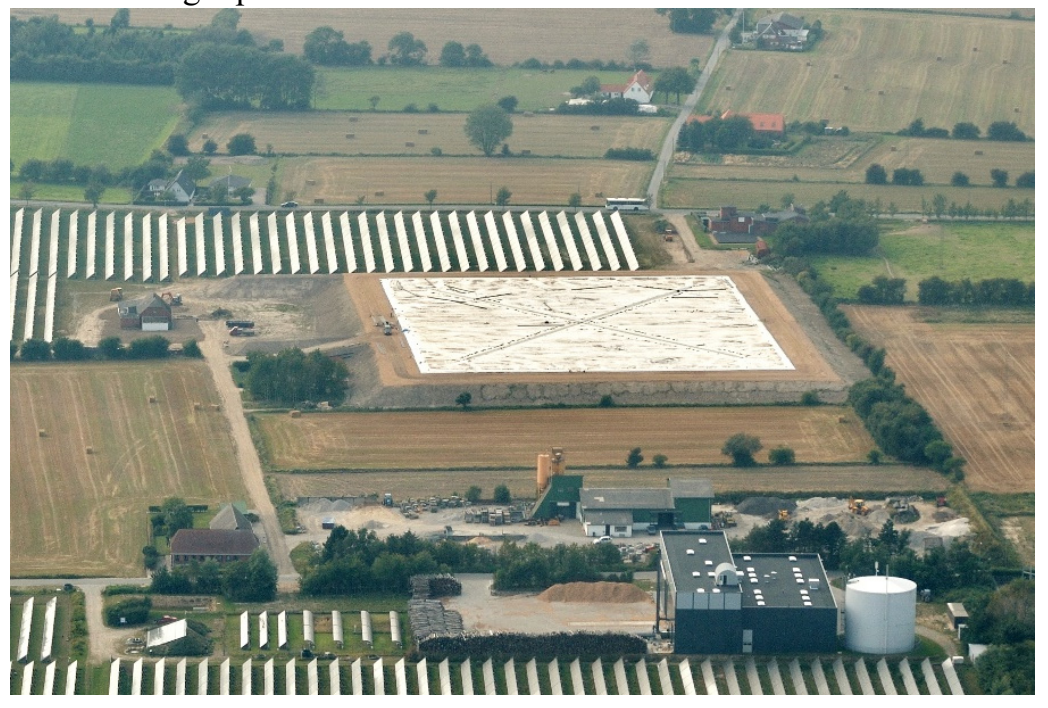

Fig. 1: Bird view of the water pit heat storage in Marstal Solar heating plant

The sensors in the inlet/outlet pipes are located at the end of the transmission pipes $300 \mathrm{~m}$ away from the pit storage. The volume flow rate is measured with flow meters in $\mathrm{m}^{3} / \mathrm{h}$ with an accuracy of $2 \%$ (Schmidt 2013). The temperature sensors are PT resistance thermometers with an accuracy of +/- $0.1 \mathrm{~K}$ (Schmidt 2013).

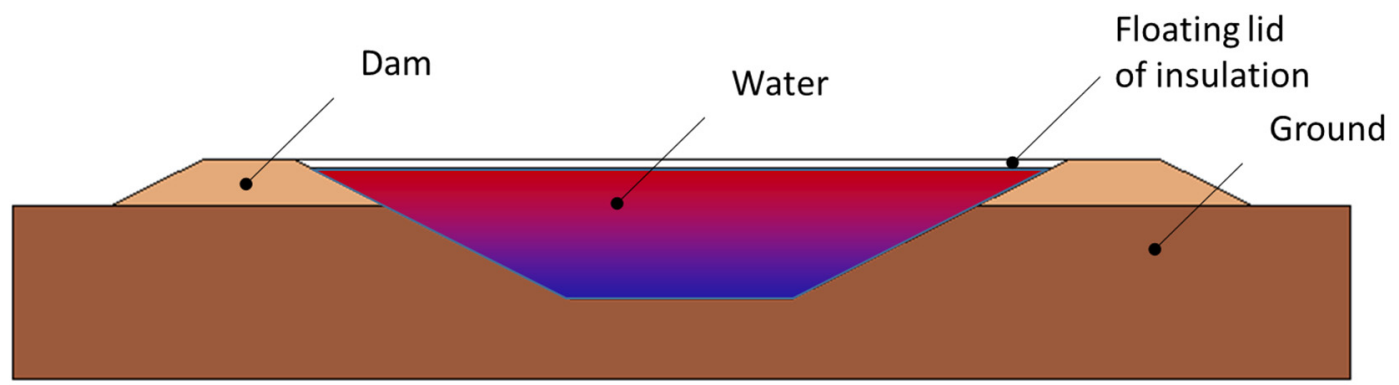

Fig. 2: Illustration of the design of a water pit thermal energy storage

The placement of the sensors in the water pit heat storage are indicated as circles in Fig. 3, where sensors A1 and A2 
measure water temperatures of the store at different depths, while the sensors B, C and G measure temperatures of the ground at different levels. Moreover, at A1 a heat flux sensor is installed in the lid including one temperature sensor on the top and one temperature sensor on the bottom surface of the insulation layer.

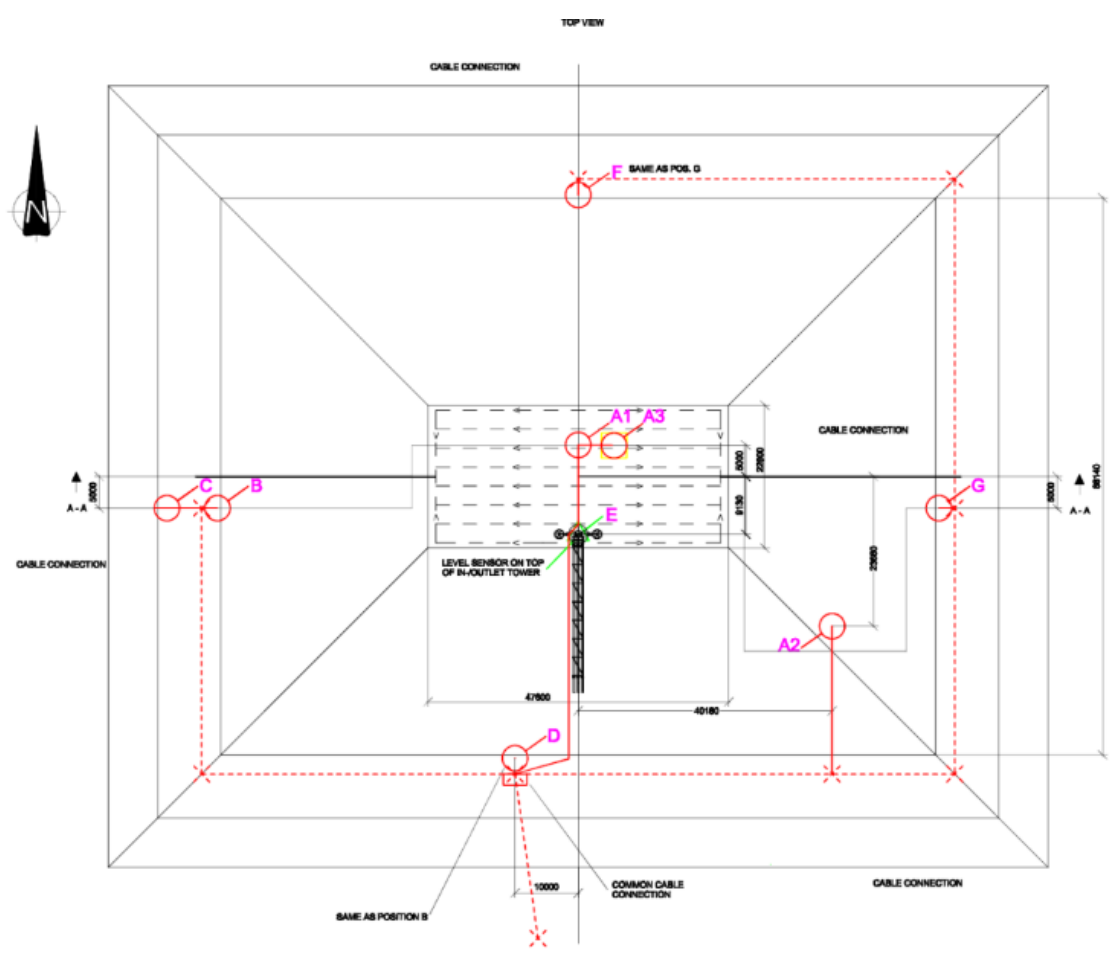

(A)

Fig. 3: Schematic illustration of the measurement sensors

\section{Numeric method}

A simplified CFD model of the water pit heat storage in Marstal is built using a commercial CFD software Ansys Fluent (Ansys 2016). The model includes the water volume in the store and the inlet/outlet openings. An inlet/outlet pipe with three inlet/outlet openings is placed in the middle of the PTES. Fig. 4 shows mesh of the simplified CFD model of the PTES. Grid lines on the side and the bottom surfaces of the PTES and grid lines on two vertical cut planes across the middle of the inlet/outlet pipe are presented. In the area around the inlet/outlet pipe, a denser mesh is assigned in order to better resolve fluid flow and heat transfer caused by inlet and outlet flows. In total 1.6 million hexahedron elements were used to mesh the model.

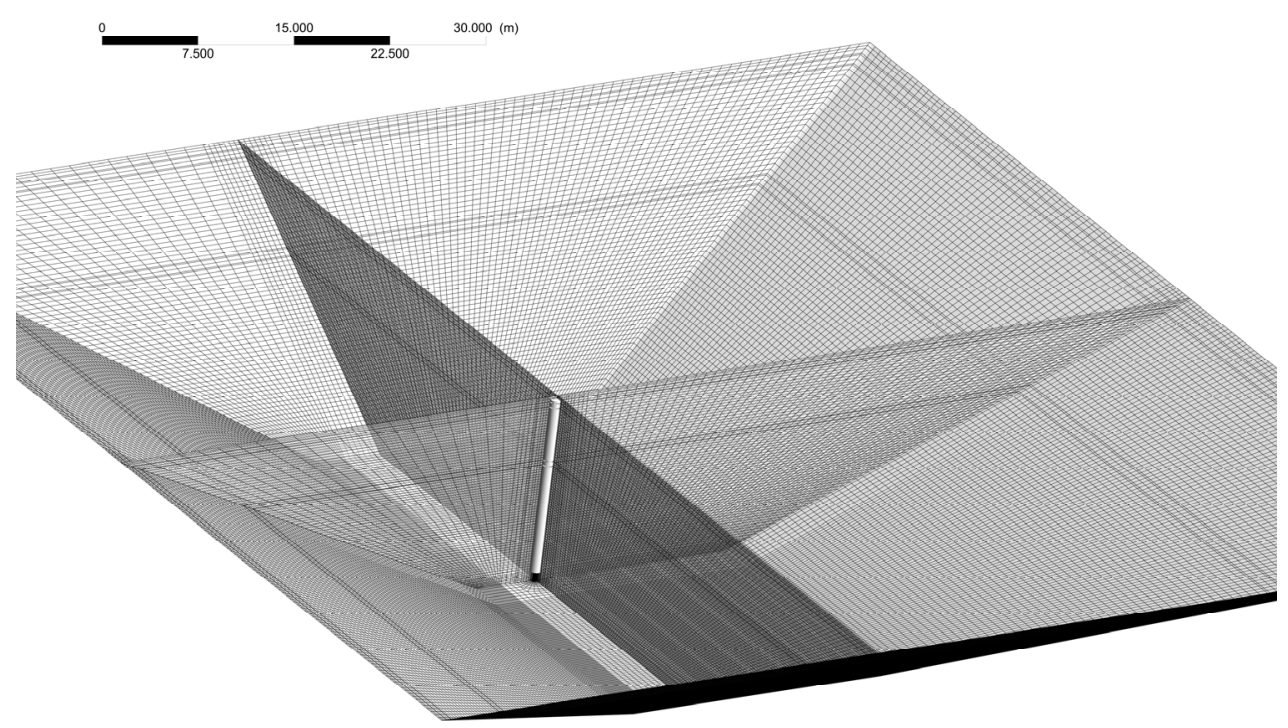

Fig. 4: Mesh of the simplified CFD model of the PTES in Marstal 
Heat loss coefficients for the top cover is determined based on given design of the floating lid and on measurements by a heat flux sensor at A1 while heat loss coefficients and boundary conditions for the side and the bottom surfaces of the store are evaluated by transient simulations using a simplified 2D CFD model of the ground around the store. Fig. 5 shows the 2D model of the water pond and the ground around the pond. It is assumed that the pond is symmetrical therefore only half of the water pond is modelled. The whole model has a dimension $74 \mathrm{~m} * 41 \mathrm{~m}$ with an aim to minimize the thermal influence of the pond on the bottom and the side boundary surfaces. Since temperature at the bottom and the side boundary surface of the 2D model is not influenced by the pond during the investigated 4 months period, these boundary surfaces are defined as adiabatic walls.

The 2D model calculates the heat transfer between the water pond surface and the ground around the store, which is used to determine heat loss coefficients of the bottom and the side surface of the PTES. The obtained heat loss coefficients are used as input in calculations using the 3D CFD model of the PTES.

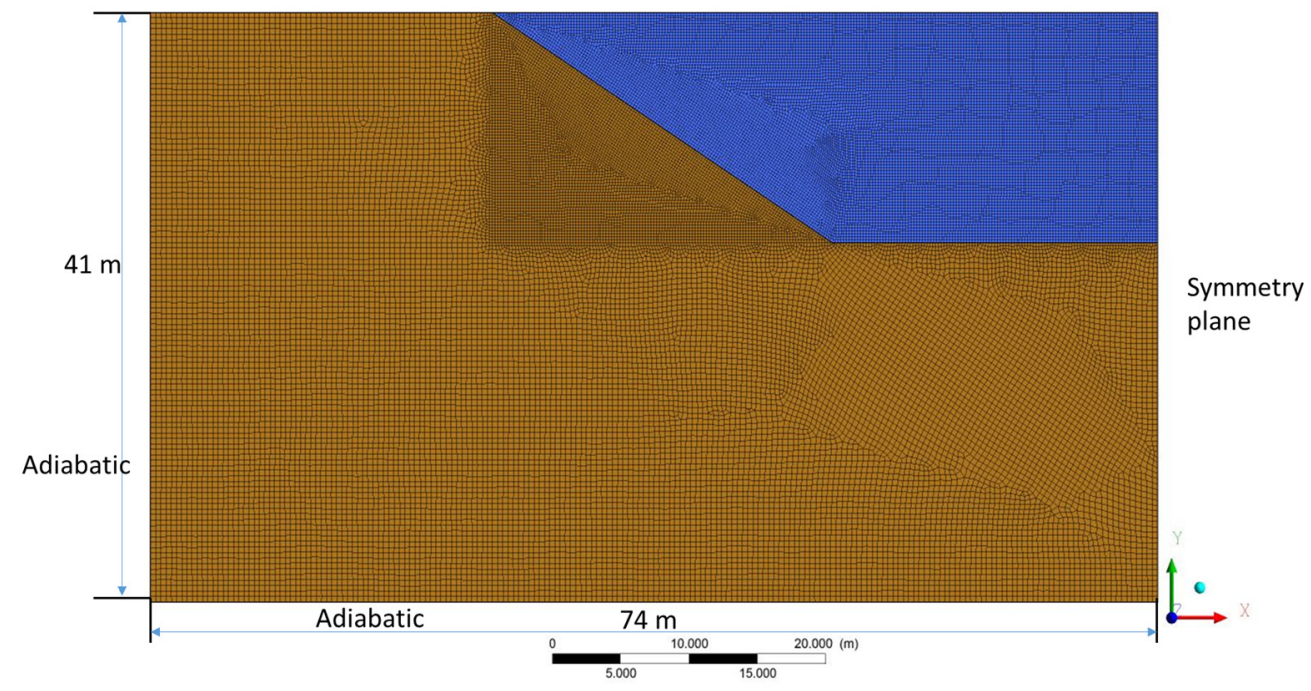

Fig. 5: A 2D ground model including the water pond and the ground around the pond

Water is used as the heat storage media. Properties of water and their dependences on temperature are shown as follows:

$$
\begin{array}{ll}
\text { Density, }\left[\mathrm{kg} / \mathrm{m}^{3}\right] & \rho=863+1.21 * \mathrm{~T}-0.00257 * \mathrm{~T}^{2} \\
\text { Dynamic viscosity, }[\mathrm{kg} /(\mathrm{ms})] & \mu=0.0007 *\left(\frac{T}{315}\right)^{-5.5} \\
\text { Thermal conductivity, }[\mathrm{W} /(\mathrm{mK})] & \lambda=0.375+8.84 \times 10^{-4} * T \\
\text { Specific heat, }[\mathrm{J} /(\mathrm{kgK})] & C \mathrm{p}=4432.6-1.819 * \mathrm{~T}+0.0033 * T^{2}
\end{array}
$$

where $\mathrm{T}$ is fluid temperature, $[\mathrm{K}]$.

Calculation of Rayleigh number shows that the flow in the PTES is laminar in most parts of the store, therefore the laminar model is used in the calculation. Transient CFD calculations are performed with Boussinesq approximation. The PRESTO and second order upwind method are used for the discretization of the pressure and the momentum/energy equations respectively. The SIMPLE algorithm is used to treat the pressure-velocity coupling. The transient simulations start with a temperature distribution in the PTES determined by measurements. A zero velocity field is assumed at the start of all simulations. The calculation is considered convergent if the scaled residual for the continuity equation, the momentum equations and the energy equation are less than $10^{-3}, 10^{-3}$ and $10^{-6}$ respectively. The simulation runs with a time step of $5 \mathrm{~s}$ and a duration of 7-10 $\mathrm{h}$.

\section{Heat losses from the store}

One important boundary of the model is thermal losses of the store which consists of two heat losses: losses from the top floating cover to the ambient air and losses from water in the pond to the ground. Heat loss from the top cover of the store is determined based on measurement by a heat flux sensor placed on the cover and properties of the 
insulation material, see location A1 in Fig. 3. Since it is only a single point measurement at a fixed location, precise measurement of heat losses for the whole cover is difficult. For instance, the measurement is not able to measure extra heat losses caused by periodic ventilation of the top cover, thermal bridges through the manhole, joints and extra heat losses caused by decreased insulation property of deformed insulation material observed in some places of the cover. The measured heat loss from the cover is therefore modified with an aim to achieve an energy balance of the water pond in a measurement period of one year. The heat fluxes of the floating cover used in the paper are in the range of $22-34 \mathrm{~W} / \mathrm{m}^{2}$.

Tab. 1: Heat fluxes from the top floating cover

\begin{tabular}{|c|c|}
\hline Days calculated by the 3D CFD model & Heat flux from the top cover $\left[\mathrm{W} / \mathrm{m}^{2}\right]$ \\
\hline October 07 & 34 \\
\hline August 03 & 24.2 \\
\hline February 18 & 22 \\
\hline April 22 & 24.2 \\
\hline
\end{tabular}

From Table 1, it can be seen that among the four days investigated, the heat flux is the largest on October 07 and the smallest on February 18. It can be explained by the temperature difference between the water at the top layer of the pond and the ambient air. On October 07 , the water pond had a relatively higher temperature due to charging during the summer while the ambient air temperature is around $10-20^{\circ} \mathrm{C}$. In February 18 , the ambient air temperature is much lower and the temperature at the top layer of the pond was significantly decreased due to discharge of the PTES throughout the winter.

Heat losses from the PTES to the ground are more difficult to measure since it is influenced not only by yearly fluctuation of the ambient air temperature, but also by heat transfer in the soil. In order to locate a ground boundary of the water pond that is not influenced by temperatures of the water pond, a large amount of soil volume has to be included in the CFD model. As a result, the CFD model might be extremely large, making it too time consuming to carry out CFD simulations. In this paper, heat transfer between the water pond and the ground is calculated in a separate 2D model, see Fig. 5. In the 2D model, measured temperatures at different layers of the water pond were used as initial conditions of the store. Fig. 6 shows temperature distribution in a vertical cut plane of the ground around the PTES. View of the whole water pond is shown in the figure to the left while a magnified view of the upper corner of the PTES is shown to the right.

The 2D ground model calculates the heat transfer between the water pond surfaces and the ground around the store, which is used to determine heat loss coefficients of the water pond surfaces. The heat loss coefficients are used as input in the 3D CFD model of the PTES.
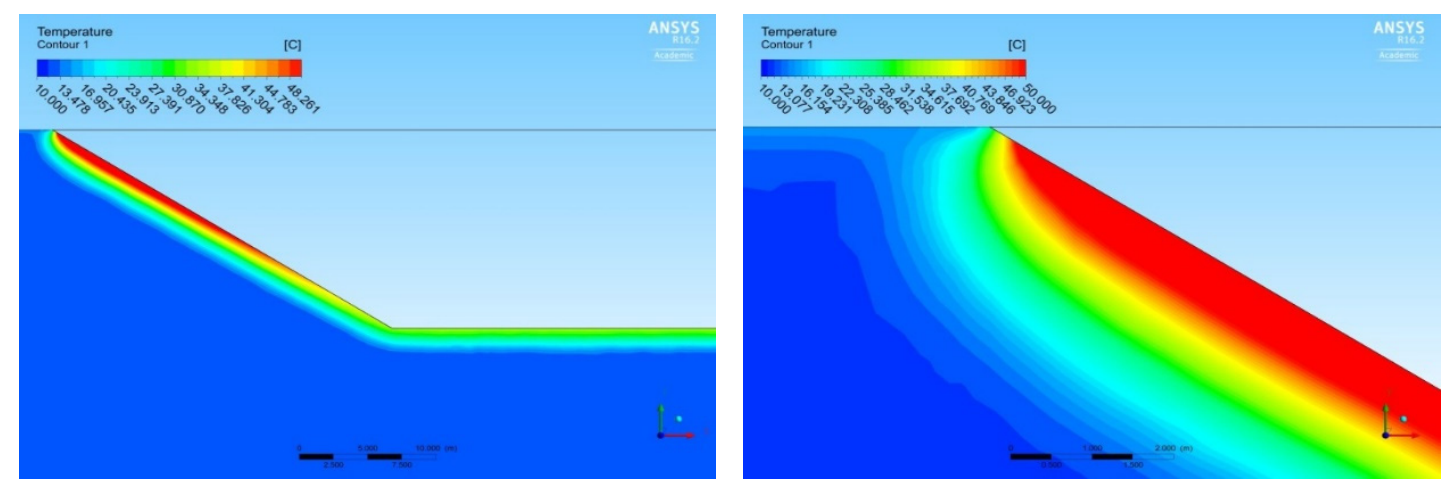

Fig. 6: Temperature distribution in a vertical cut plane of the ground around the PTES (left: side and bottom surface, right: a magnified view of the upper corner of the PTES )

Fig. 7 shows the calculated heat transfer coefficients between the sides of the water pond and the ground soil. The blue curve and the orange curve show respectively the heat transfer coefficients obtained by the simplified 2D model and the coefficients used in the 3D CFD model by means of a user defined function. As shown in Fig. 7, the heat loss coefficient of the sides of the PTES is around $0.15 \mathrm{~W} / \mathrm{m}^{2} / \mathrm{K}$ at a depth of 16 meters. The heat loss coefficient increases slightly with a decrease of the depth. At a depth of 2 meters, the heat loss coefficient is around $0.2 \mathrm{~W} / \mathrm{m}^{2} / \mathrm{K}$. For surface area within 2 meters deep, the heat loss coefficient increases significantly due to the influence of ambient 
conditions. At the bottom surface of the PTES, the heat loss coefficient is found to be $0.1 \mathrm{~W} / \mathrm{m}^{2} / \mathrm{K}$.

\section{Heat Transfer Coefficient to Ground}

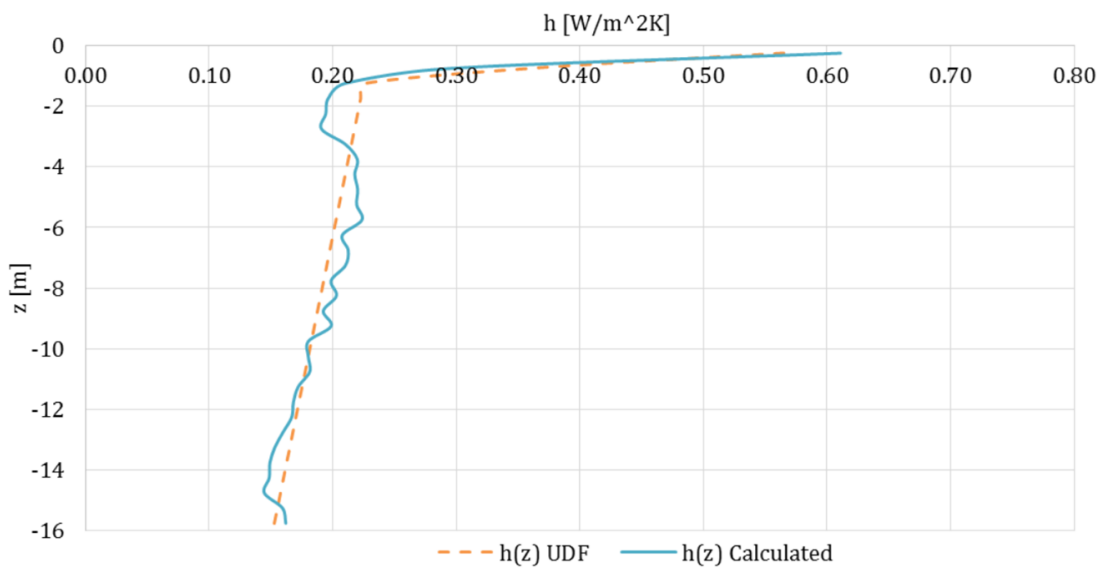

Fig. 7: Heat transfer coefficients between the sides of the water pond and the ground soil.

The 2D ground model was also used to determine soil temperature around the water pond. Since temperature of the ground around the store depends on both the depth of the soil and the time of the year, the distribution pattern of the temperatures was determined by calculation using the 2D ground model, while the absolute level of the temperature was determined by measurements at the location B.

Fig. 8 shows ground temperatures on the side of the water pond in different times of the year. Among the investigated four periods, the ground soil temperature is the highest in October and the lowest in February, which indicates a strong influenced by the temperatures of the pond and the ambient air. A clear pattern can be seen from the curves: relatively lower temperature at both the top and the bottom of the pond and higher temperature around $6 \mathrm{~m}$ below the ground surface. A lower temperature at the bottom of the pond could be explained by strong thermal stratification in the pond. Due to thermal stratification, temperature of water layer at the bottom of the pond is relatively lower, therefore a lower temperature is observed at $16 \mathrm{~m}$ below the ground surface. While a lower temperature close to the ground surface could be explained by cooling of soil by the ambient air with a lower temperature.

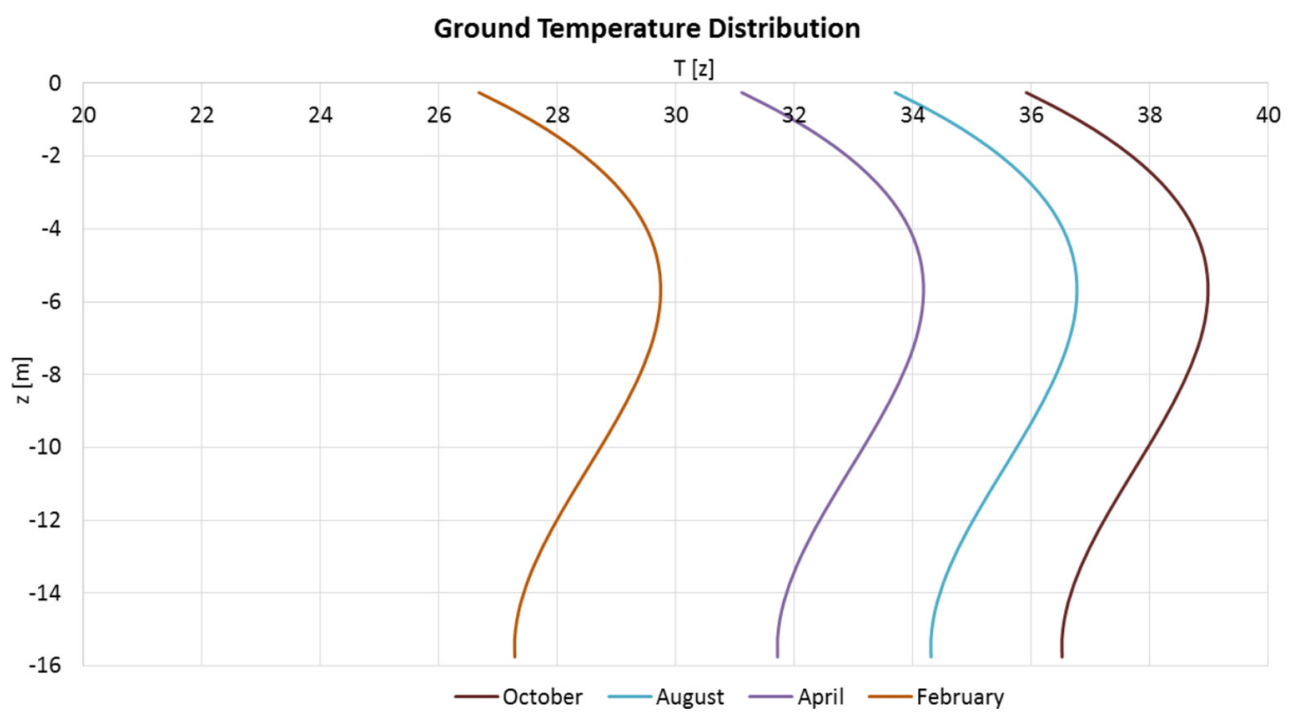

Fig. 8: Ground temperature on the side of the water pond

\section{Thermal stratification in PTES}

Validity of the CFD model is investigated by comparing the CFD calculated thermal behaviors of the PTES with the measurements. The investigation was carried out for 4 scenarios including two discharges and two charges of the PTES, see Table 2. In the CFD simulations measured temperatures of the water pond and the ground were used as initial conditions of the PTES. The transient flow rate and temperature of the inlet flow to the PTES were measured 
and used as boundary conditions for the inlets by means of user defined functions. During charge of the PTES, the average temperatures of the inlet flow are $83.3^{\circ} \mathrm{C}$ and $77.3^{\circ} \mathrm{C}$ on August 03 and April 22 respectively. The average discharge temperature are $44.4^{\circ} \mathrm{C}$ and $36.5^{\circ} \mathrm{C}$ respectively on October 07 and February 18. The CFD calculated temperatures at the outlet and at different levels of the pond were compared to the measured ones.

The CFD model is able to calculate heat transfer and the convective, buoyance driven flow in the PTES. The development of water temperature is elucidated by means of the transient CFD simulations. Thermal stratification in the store during charge and discharge of the store is evaluated.

Tab. 2: Heat fluxes from the top floating cover

\begin{tabular}{|c|c|c|c|c|c|}
\hline $\begin{array}{c}\text { Days calculated } \\
\text { by the 3D CFD } \\
\text { model }\end{array}$ & $\begin{array}{c}\text { Initial pond T at } \\
\text { the bottom, }{ }^{\circ} \mathbf{C}\end{array}$ & $\begin{array}{c}\text { Initial pond T at } \\
\text { the top, }{ }^{\circ} \mathbf{C}\end{array}$ & $\begin{array}{c}\text { Average ground } \\
\mathbf{T} 2.5 \text { m from } \\
\text { pond surface, }{ }^{\circ} \mathbf{C}\end{array}$ & $\begin{array}{c}\text { Average inlet T, } \\
{ }^{\circ} \mathbf{C}\end{array}$ & $\begin{array}{c}\text { Measured } \\
\text { energy, } \mathbf{M W h}\end{array}$ \\
\hline October 07 & 44 & 82 & 37.8 & Discharge, 44.0 & 24.2 \\
\hline August 03 & 52 & 79 & 35.6 & Charge, 83.3 & 68.9 \\
\hline February 18 & 30 & 51 & 33.0 & Discharge, 36.5 & 14.6 \\
\hline April 22 & 33 & 71 & 28.5 & Charge, 77.3 & 95.3 \\
\hline
\end{tabular}

\subsection{Charge of the PTES}

Fig. 9 shows the measured and the CFD predicted charge power of the PTES for the charge case on August 3. There is a satisfactory agreement between the CFD model and the measurements. The difference between the measured energy flow and the calculated energy flow is within $10 \%$.

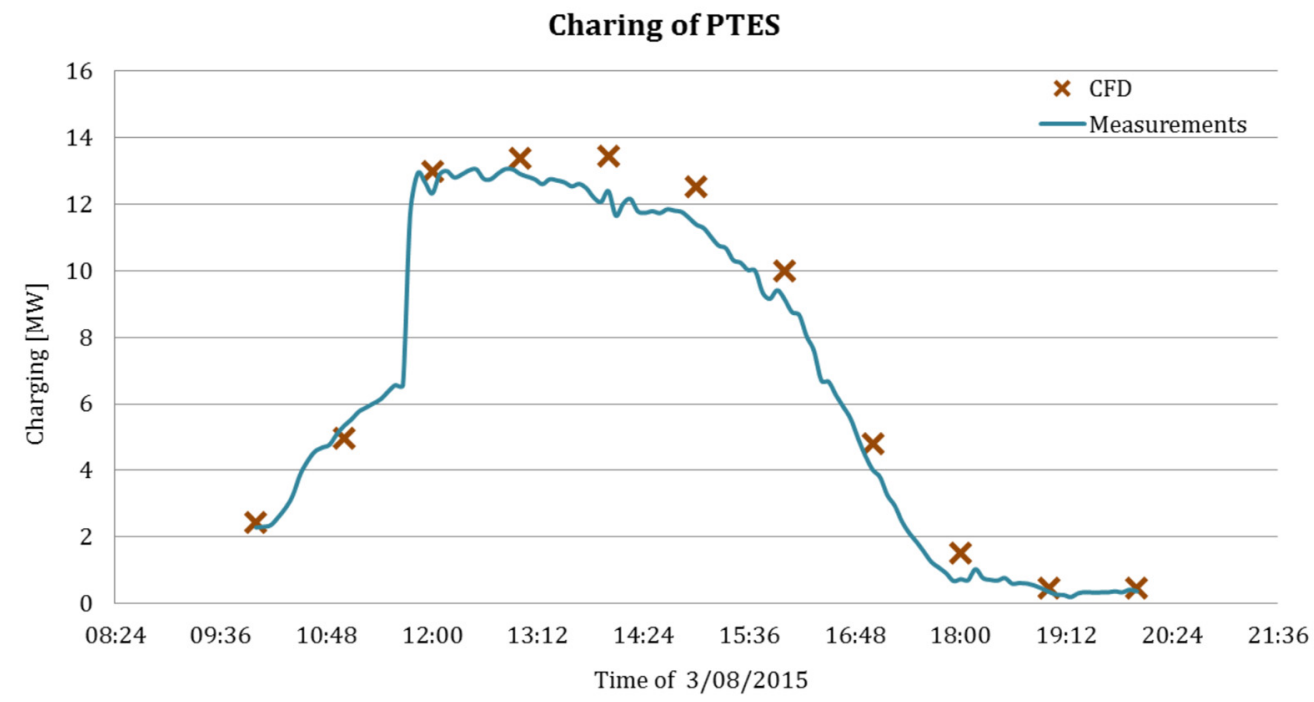

Fig. 9: Measured and CFD predicted charge power of the PTES for the case on August 3

Fig. 10 shows the measured and the CFD predicted temperature distributions in the PTES for the case on August 3. Both the initial temperatures and the temperature distribution of the pond at the end of the calculation are presented. The measured temperatures are shown as scatted dots while the CFD calculated temperatures are shown as curves. A comparison between the measured and the CFD calculated temperatures is shown for the location A1 and A2 respectively in the figure to the left and the figure to the right. Since the depths of the water are 16 meter at the location A1 and 8 meters at the location A2, the scales of the two figures are different. It is shown that water at the same level of the pond has almost identical temperatures. Based on the measured initial temperatures at different levels of the water pond in the start of the charge period, a regression is made to find a function between the water temperature and levels of the pond. The function is used as initial conditions in the CFD model by means of user defined functions.

There is generally a good agreement between the measured and the CFD calculated temperatures at the end of the charge period (20:00) at different locations of the pond. An exception is found at the level of $4 \mathrm{~m}$ below the ground surface on the location $\mathrm{A} 2$ where the water temperature was measured to be approx. $85^{\circ} \mathrm{C}$ in comparison to a CFD calculated temperature of around $75^{\circ} \mathrm{C}$. A likely cause of the big difference could be false measurement of the sensor. 
As water temperatures at the top of the pond are approx. $80^{\circ} \mathrm{C}$, it is very unlikely that temperature of the water 4 meter below the surface has a temperature higher than temperature of the water on the top of the pond. Therefore measurement data of the false sensor was not included in the investigations.

In the right figure of Fig. 10, it is shown that measured temperature of water at the top surface of the pond has a lower temperature than water 1-4 meter below the water surface, indicating a higher heat loss from the top cover at the location A2 than the average heat loss used in the CFD model.

It should be noted that temperature of the water pond increases slightly during charging in the investigated period. Such a change of temperature during charge in one day is too small to fully validate the CFD model. CFD calculation of charging in more than one day would better elucidate validity of the CFD model but the corresponding simulation time would increase significantly, therefore was not applicable for the present study. However such long term calculations are recommended for the future by means of parallel computing on super computers.
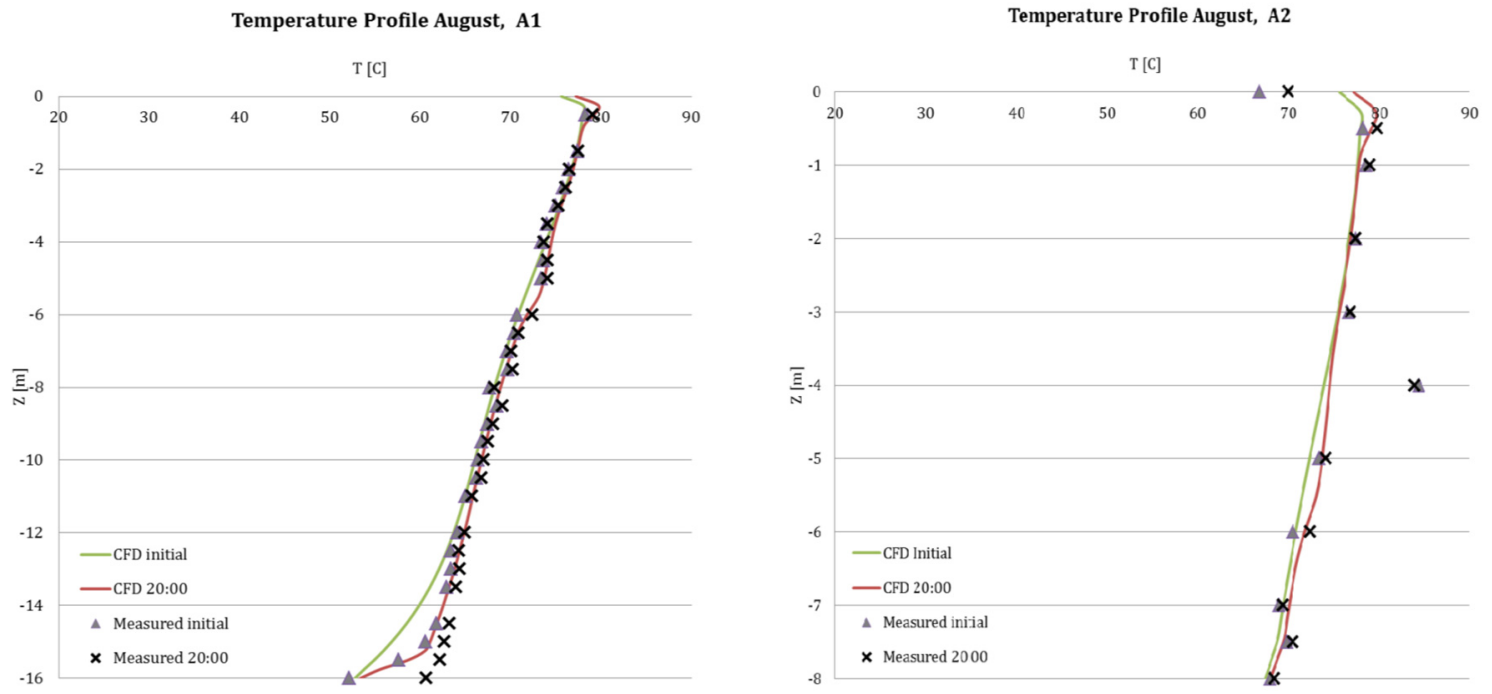

Fig. 10: Measured and CFD predicted temperature distribution in the PTES for the charge case on August 3

Fig. 11 shows temperature plots in the water pond at different times of the day. Temperature distributions at the start of the charge period (10:00) and in the middle of the day (14:00) are shown respectively in Fig. 11A and 11B. As shown in Fig. 11B, there are inlet flows with a temperature of $85^{\circ} \mathrm{C}$ in the top inlet and in the middle inlet. After entering the top inlet opening, the hot fluid rises up and tends to flow along the top surface of the pond. Around the middle inlet opening, the inlet hot fluid mixes with relatively colder water in the PTES, resulting in a mixing region above the inlet opening. The mixing region is limited to a small area around the inlet disc indicating a good conservation of thermal stratification in the pond.

Fig. 12 shows regions in the pond where there is a larger fluid movement. Not surprisingly, larger fluid movement is observed in the three regions: around the top inlet opening, the middle inlet opening and the exit. The fluid velocity close to the inlets are in the range of 4-8 $\mathrm{cm} / \mathrm{s}$, which are considered to be higher enough to destroy thermal stratification. Since the region with a disturbing fluid velocity is rather limited, thermal stratification in the pond is kept during charge of the pond. It is interesting to note that around the top inlet opening the region with a higher fluid movement looks like a disc, indicating spreading of the hot fluid along the top surface of the PTES. That fluid pattern means well function of the inlet opening since the hot fluid has a higher temperature than the water temperature at the top of the pond and therefore should be directed by the inlet to the very top of the pond. 


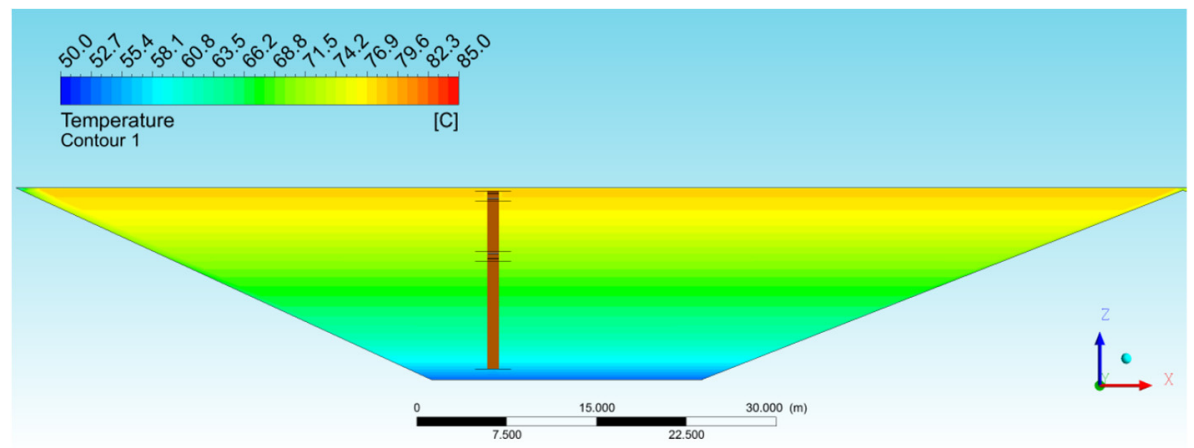

(A) Thermal stratification at 10:00

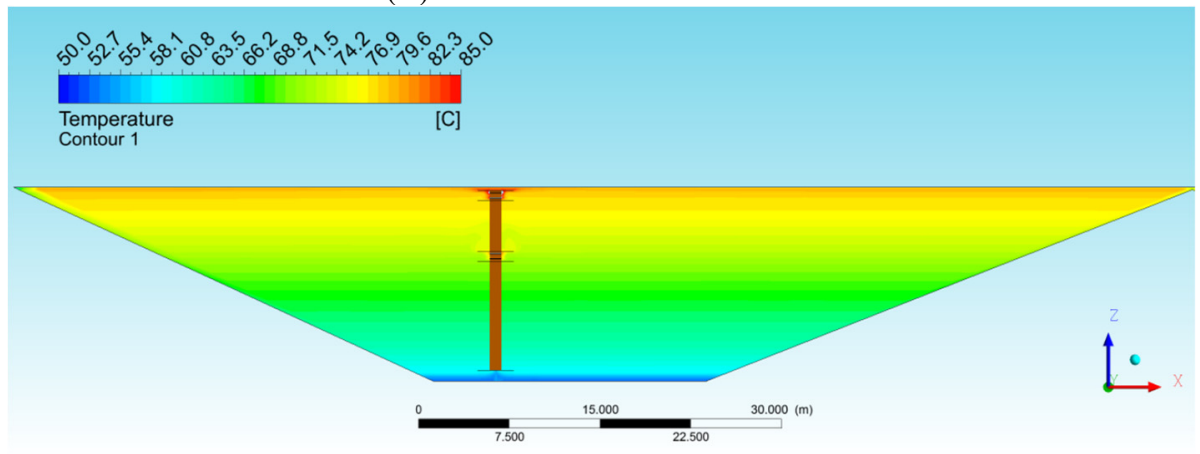

(B) Thermal stratification at 14:00

Fig. 11: Temperature plots of the water pond during charge on August 3

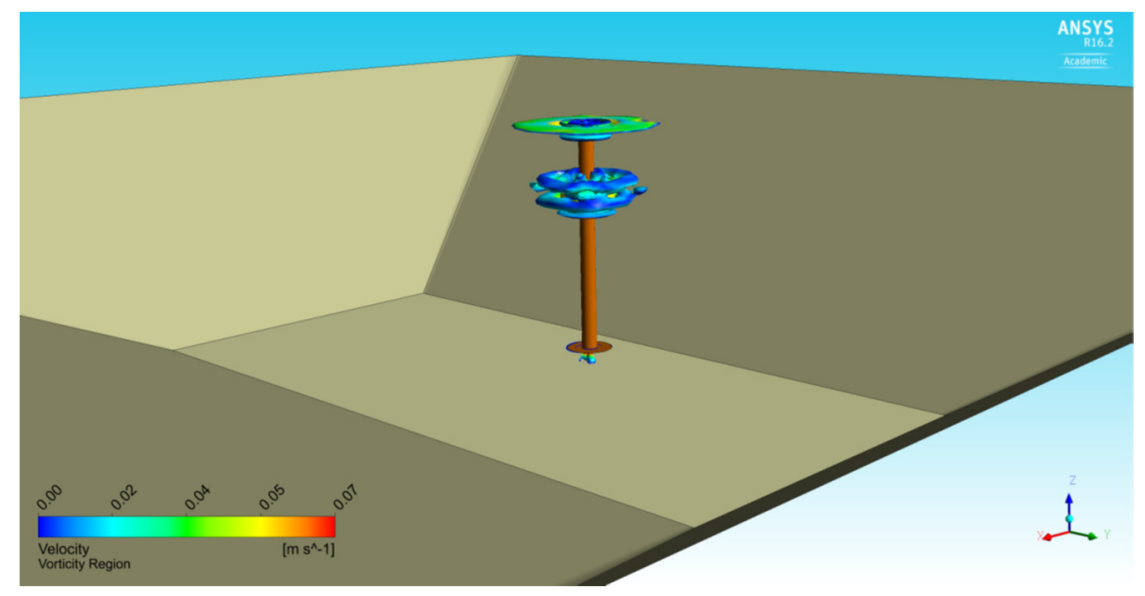

Fig. 12: Illustration of regions with a larger fluid movement for the charge case on August 3

\subsection{Discharge of the PTES}

Fig. 13 shows the measured and the CFD predicted discharge power of the PTES for the discharge case on October 7. There is a satisfactory agreement between the CFD model and the measurements. The difference between the measured energy flow and the calculated energy flow is within 5\% except at the very start of the simulation. There is a large difference of approx. 0.4 MW between the measured and the calculated discharge power. A large deviation at the start of the simulation could be due to over simplified initial conditions of the PTES in the CFD model. 


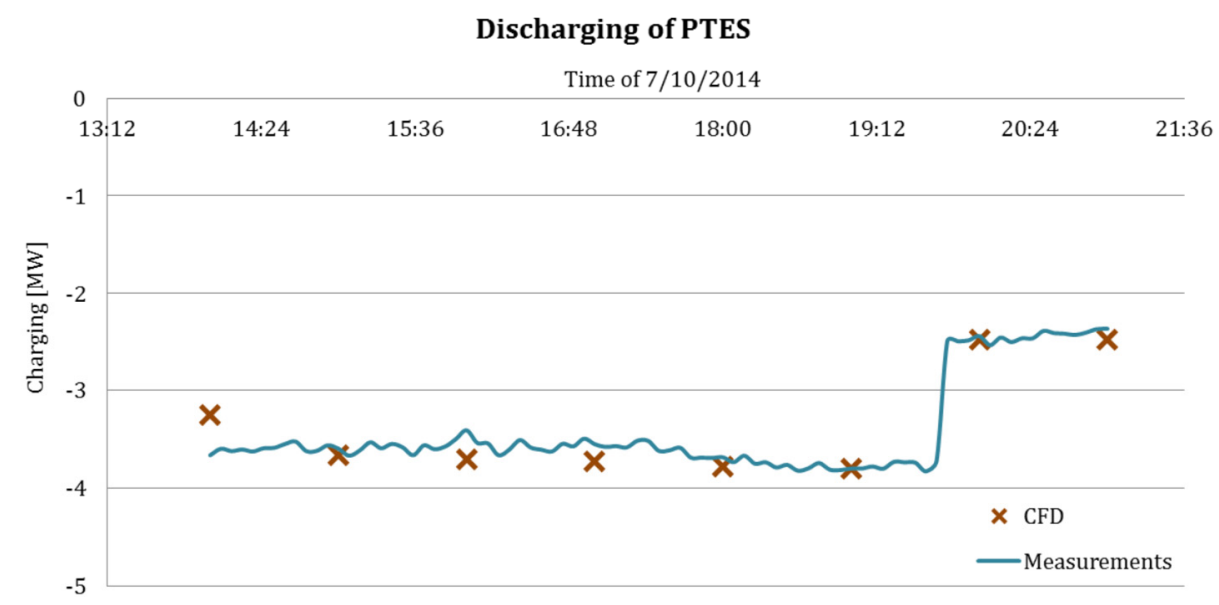

Fig. 13: Measured and CFD predicted discharge power of the PTES for the discharge case on October 7

Fig. 14 shows temperature distribution in the water pond at 21: 00 October 7. A clear thermal stratification in the pond can be observed. At the start of the October the pond was already quite fully charged. Water temperatures are $80-87^{\circ} \mathrm{C}$ in the top of the pond, $70-76^{\circ} \mathrm{C}$ in the middle and $40-45^{\circ} \mathrm{C}$ at the bottom of the pond. During discharge, hot water is taken from the top of the pond, cooled down by the district heating network and returns through the bottom inlet of the pond. Since the inlet water is around $44^{\circ} \mathrm{C}$, close to the water temperature at the bottom of the pond, there is almost no mixing induced by the inlet flow. It is also confirmed by Fig. 15 where regions with a fluid velocity larger than $3 \mathrm{~cm} / \mathrm{s}$ can be seen. Around the inlet opening at the bottom, the mixing region is very much limited. It can concluded that the current inlet/outlet design is able to minimize mixing during discharge from the top and the bottom openings when the PTES is fully charged.

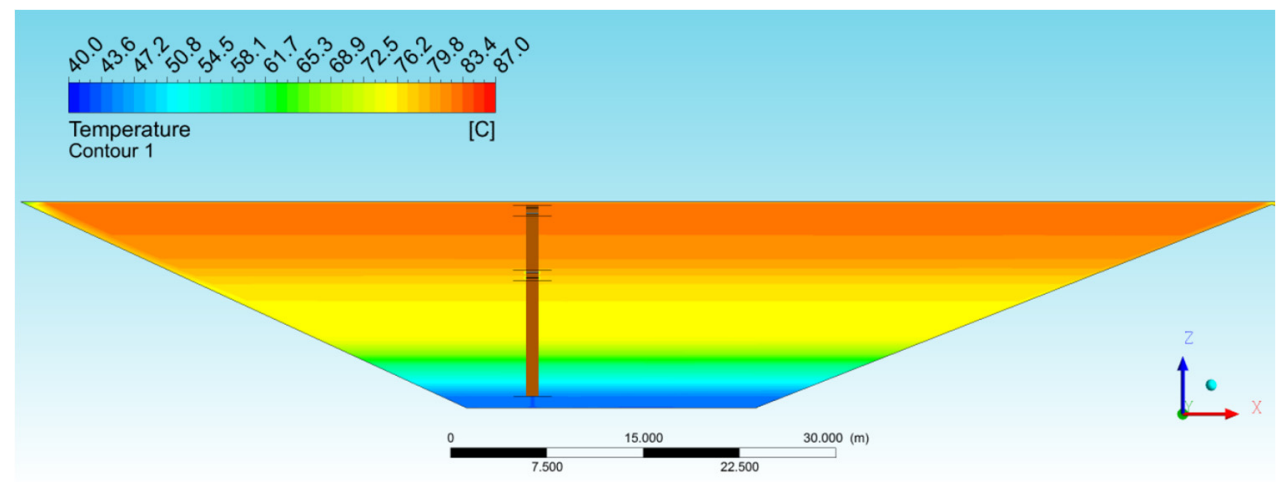

Fig. 14: Temperature plot of the water pond at 21:00 for the discharge case on October 7

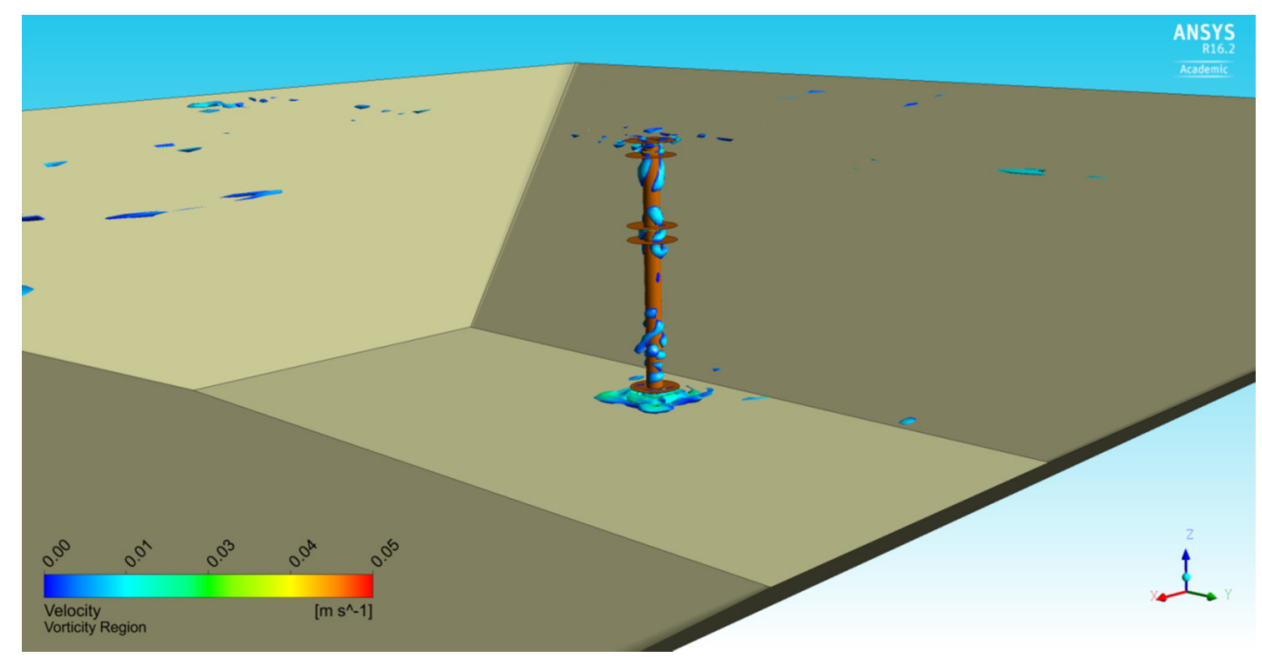

Fig. 15: Illustration of regions with a larger fluid movement for the discharge case on October 7

Fig. 16 shows temperature distribution in the water pond at 6:00 February 18 during discharge. After discharge throughout the winter, temperature of the pond was significantly decreased. Water temperature at the top of the pond was decreased to $48-53^{\circ} \mathrm{C}$ while the water temperature was in the range $28-32^{\circ} \mathrm{C}$ below the middle opening. During 
the discharge, heat is taken from the top of the pond as for instance heat source of a heat pump. On the hot side of the heat pump, the district heat water is heated from $40^{\circ} \mathrm{C}$ to $80-85^{\circ} \mathrm{C}$. On the cold side the heat pump, water is cooled down from $48-53^{\circ} \mathrm{C}$ to around $40^{\circ} \mathrm{C}$ before flowing back to the pond through the bottom inlet opening. Since the inlet water temperature is higher than the water temperature at the bottom of the pond, a significant mixing at the lower part of the pond is observed, see Fig. 17. Due to buoyancy forces, the incoming water with a higher temperature rises along the inlet/outlet pipe while water on the edge of the pond with a relatively lower temperature flows down to the bottom of the pond, creating a big circulation and a quite uniform temperature at the lower part of the pond. The circulation is shown by the stream lines in Fig. 18.

Velocity vectors in the water pond during discharge on February 18 are shown in Fig. 18. A clear uprising flow is seen along the inlet/outlet opening. After reaching the middle opening where there is a water layer with higher temperature, the flow turns to flow horizontally.

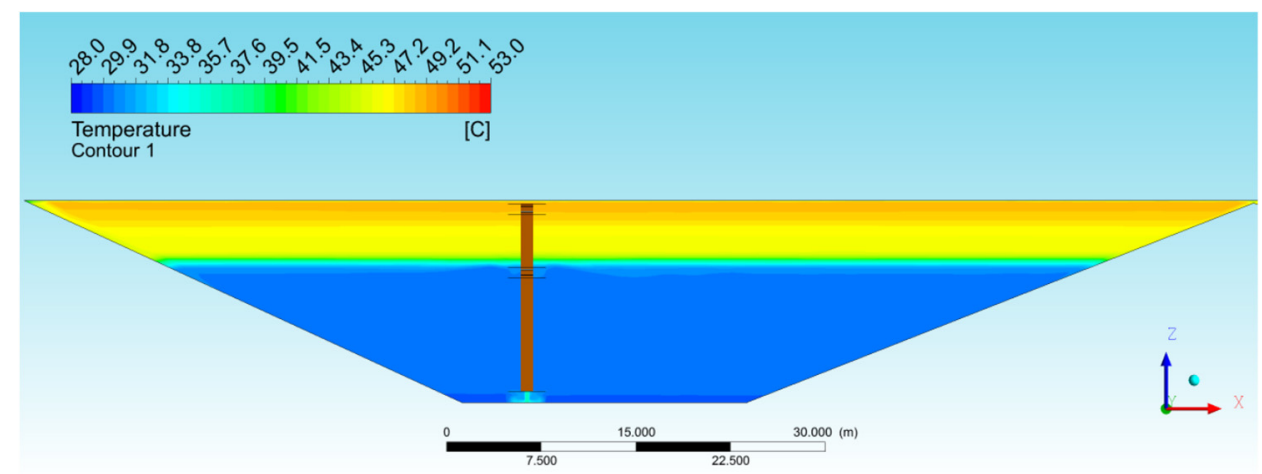

Fig. 16: Temperature plot in the water pond at 6:00 for the discharge case on February 18

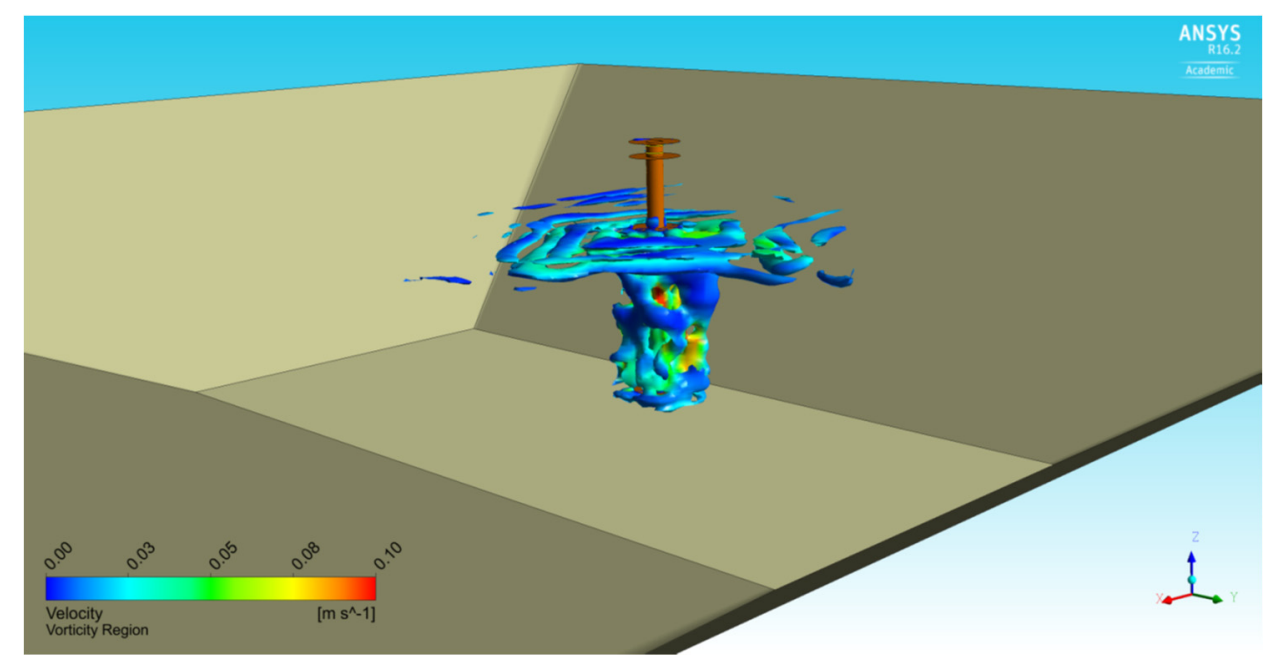

Fig. 17: Illustration of regions with a larger fluid movement for the discharge case on February 18
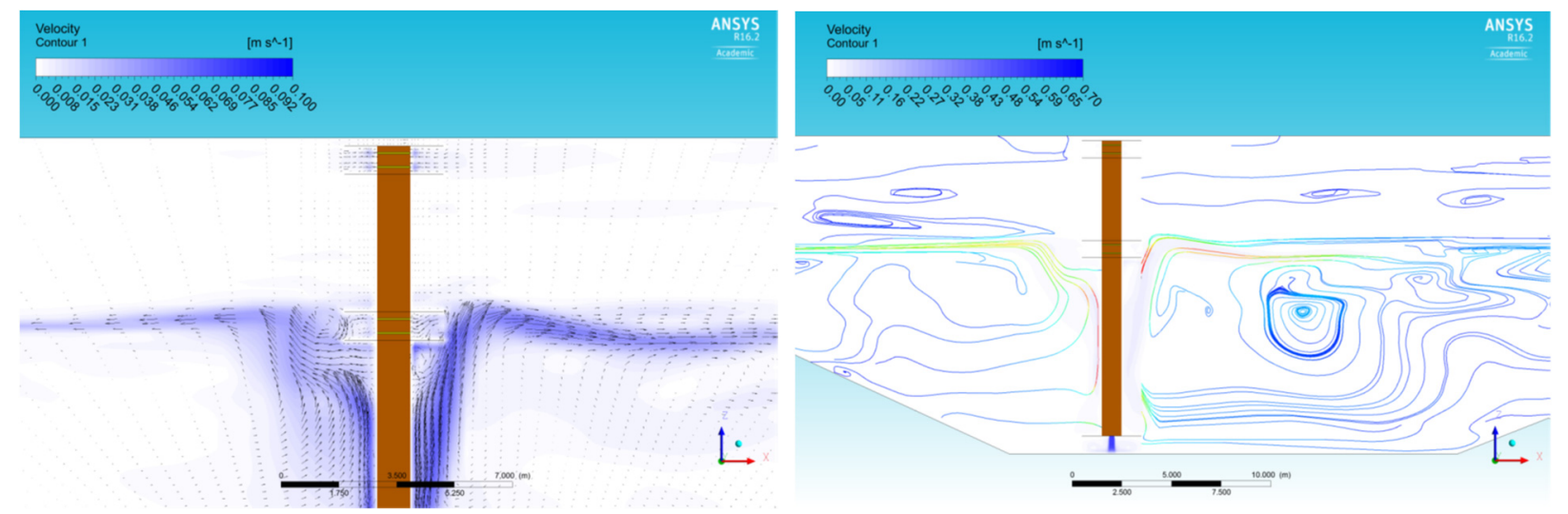

(A) Velocity vectors showing the uprising flow (B) Stream lines shown a big circulation

Fig. 18: Velocity vectors and stream lines in the water pond during discharge on February 18

For the investigated scenario, the inlet temperature is much higher than the temperature at the bottom of the pond, 
thus creating strong mixing and destroying stratification at the lower part of the pond. If the middle inlet opening was used as inlet, a better thermal stratification in the pond could be achieved. However it should be mentioned that temperature of water from the heat pump varies depending on operation conditions of the heat pump. The return temperature could be much lower under some conditions, for instance a return temperature from the heat pump in the range of $15-25^{\circ} \mathrm{C}$ is likely to happen. Consequently it will be advantageous to have the inlet at the bottom inlet opening. It is therefore interesting to investigate these scenarios in detail in the future.

\section{Conclusions}

Thermal behaviors of the $75,000 \mathrm{~m}^{3}$ water pit heat storage in Marstal solar heating plant were investigated experimentally and numerically. Temperatures at different levels of the water pit storage and temperatures at different depths of the ground around the storage were monitored and analyzed. A simulation model of the water pit storage is built to investigate development of temperature in and around the storage. The calculated temperatures are compared to the monitored temperatures with an aim to validate the simulation model. The results show that the CFD models predict satisfactorily temperatures in the PTES for both charge and discharge operations. However it is recommended for the future to carry out a long term simulation in order to achieve a more detail validation of the CFD models.

Calculations of fluid flow and heat transfer in the PTES by the CFD model show that the inlet/outlet openings work properly during charge with minimal mixing region created in the PTES around the inlet/outlet openings. While for discharge of PTES, the ability of the inlet/outlet arrangement to keep thermal stratification strongly depends on temperature of water returned to the PTES. If temperature of the flow back to the PTES is much higher than the temperature at the bottom of the pond, strong mixing will be created, thus destroying stratification at the lower part of the pond. If the return temperature is lower than temperature at the bottom part of the PTES, it will be advantageous to have the inlet at the bottom inlet opening. It is therefore recommended to investigate these scenarios in future studies.

\section{References}

Ansys Inc., 2016. Ansys Fluent release 17.0, Southpointe, 2600, Ansys Drive, Canonsburg, PA 15317, USA.

Heller A., 2000. 15 Years of R\&D in central solar heating in Denmark. Solar energy, 69, 437-447.

Chang C., Wu Z., Navarro H., 2017, Comparative study of the transient natural convection in an underground water pit thermal storage, Applied Energy, in press.

Jensen M.V., 2014. SUNSTORE $® 4$ Design of the Water Storage The SUNSTORE Plant in Marstal. In Sunstore 4 Design of the Water Storage.

Kate D. Sunstore4. http://sunstore4.eu/, 2013. [Online; accessed 01-04-2017].

Kielsgaard Hansen, K., Nordgaard Hansen, P., Ussing, V., 1983. Seasonal heat storage in underground warm water stores. Report 134, Thermal Insulation Laboratory, Technical University of Denmark.

Kübler R., Fisch N., Hahne E., 1997, High temperature water pit storage projects for the seasonal storage of solar energy Journal, Solar Energy, 61, 97-105.

Pavlov, G.K., Olesen, B.W., 2012. Thermal energy storage -A review of concepts and systems for heating and cooling applications in buildings: Part 1-Seasonal storage in the ground. HVAC\&R Research, 18, 515-538.

Pfeil M., Koch H., 2000, High performance-low cost seasonal gravel/water storage pit, Solar Energy, 69, 461-467.

Schmidt T., 2013. Sunstore 4 Technical Reports: Design of the measurement and evaluation program.Sharma A., Tyagi V. V., Chen C. R., Buddhi D., 2009. Review on thermal energy storage with phase change materials and applications. Renewable and Sustainable Energy Reviews, 13, 318-345. 